\title{
Morphological Characterization of Pulmonary Microvascular Disease in Bronchopulmonary Dysplasia Caused by Hyperoxia in Newborn Mice
}

\author{
Hidehiko Nakanishi, Shunichi Morikawa, Shuji Kitahara, \\ Asuka Yoshii, Atsushi Uchiyama, Satoshi Kusuda, \\ and Taichi Ezaki
}

\section{Keywords}

Bronchopulmonary dysplasia $\cdot$ Pulmonary hypertension $\cdot$ Pulmonary microvascular disease

Bronchopulmonary dysplasia (BPD) is one of the most significant medical complications in preterm infants, and pulmonary microvascular injury is associated with the pathogenesis of BPD [1]. Furthermore, impairments of developing pulmonary vasculature may cause secondary pulmonary hypertension $(\mathrm{PH})$, which contributes significantly to morbidity and mortality among preterm infants [2]. To characterize the mechanisms of pulmonary vascular disease resulting from BPD, we studied the ultrastructural changes affecting pulmonary microvasculature.

Newborn ICR mice were exposed to $85 \%$ hyperoxia or normoxia for 14 days, and then normal air replacement conditions for the following 7 days. At postnatal day (P)14 and P21, lungs were harvested for ultrastructural examination and assessment of PH. To this end, we studied ultrastructural changes in pulmonary microvasculature, such as endothelial cells (ECs) and blood-air barriers (BABs), and examined the structure of pulmonary arteries associated with terminal and respiratory bronchioles as well as right ventricular hypertrophy (RVH).

H. Nakanishi $(\bowtie) \cdot$ A. Uchiyama $\cdot$ S. Kusuda

Maternal and Perinatal Center Neonatal Division, Tokyo Women's Medical University,

Tokyo, Japan

e-mail: hidehiko@qf6.so-net.ne.jp

S. Morikawa $\cdot$ S. Kitahara $\cdot$ A. Yoshii · T. Ezaki

Department of Anatomy and Developmental Biology, Tokyo Women's Medical University

School of Medicine, Tokyo, Japan 

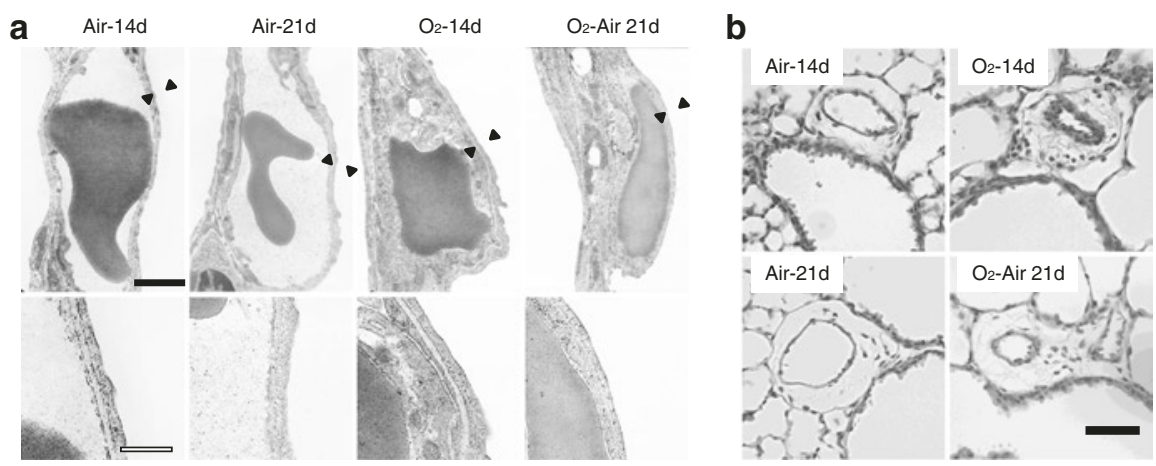

Fig. 11.1 (a) Pulmonary capillaries and blood-air barriers in Air-14d, Air-21d, O2-14d, and normal air replacement conditions after hyperoxia (O2-Air-21d). Scale bar black, $1.0 \mu \mathrm{m}$; white, $0.35 \mu \mathrm{m}$. Black arrowheads denote the parts of BABs magnified in the lower panels. (b) H\&Estained lung sections indicating the thickness of pulmonary arteries associated with terminal and respiratory bronchioles. Scale bar (black), $50 \mu \mathrm{m}$

ECs presented a heterogeneously thick and irregular cytoplasm with welldeveloped basal infoldings (Fig. 11.1a). Moreover, red blood cells inside the alveolar capillary seemed to be stuck in the capillary lumen, suggesting collapsed capillaries and altered pulmonary microcirculation. BABs from injured lungs, comprising EC, alveolar epithelial cells, and the basal lamina, were much thicker than those of air-exposed lungs, and most BABs were filled with abnormal mitochondriarich $\mathrm{EC}$ layers. In contrast, $\mathrm{BAB}$ basal lamina layers in hyperoxia-exposed lungs were not significantly different from those in controls. Even in the lungs of animals exposed to normal air replacement conditions, ECs presented a heterogeneously thick cytoplasm rich in organelles, collapsed alveolar capillaries, and EC layers occupying most of the BABs. Structural changes were accompanied by increased pulmonary artery medial thickness and RVH (Fig. 11.1b). Results were confirmed by morphometric quantification.

Pulmonary capillaries in the injured newborn mouse lung presented thick BABs consisting of ECs with abnormal morphology, which persisted following subsequent exposure to normal air replacement conditions. These ultrastructural changes might cause abnormal pulmonary microcirculation and finally lead to secondary $\mathrm{PH}$ in BPD.

Acknowledgment This study was supported by the Ministry of Education, Culture, Sports, Science and Technology (MEXT) KAKENHI (Grant Number 16K10111). 


\section{References}

1. Abman SH. Bronchopulmonary dysplasia: "a vascular hypothesis". Am J Respir Crit Care Med. 2001;164:1755-6.

2. Nakanishi H, Uchiyama A, Kusuda S. Impact of pulmonary hypertension on neurodevelopmental outcome in preterm infants with bronchopulmonary dysplasia: a cohort study. J Perinatol. 2016;36:890-6.

Open Access This chapter is licensed under the terms of the Creative Commons Attribution 4.0 International License (http://creativecommons.org/licenses/by/4.0/), which permits use, sharing, adaptation, distribution and reproduction in any medium or format, as long as you give appropriate credit to the original author(s) and the source, provide a link to the Creative Commons license and indicate if changes were made.

The images or other third party material in this chapter are included in the chapter's Creative Commons license, unless indicated otherwise in a credit line to the material. If material is not included in the chapter's Creative Commons license and your intended use is not permitted by statutory regulation or exceeds the permitted use, you will need to obtain permission directly from the copyright holder.

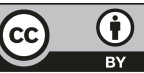

